\title{
The Future of Social
}

\section{Protection - Where Next?}

Social protection is one of the success stories of development policy in the early twenty-first century, leading to questions about its future direction. Evidence suggests that social protection is likely to experience further expansion in the future, becoming a response to income inequality and social inequities as well as to poverty and vulnerability. It will become increasingly systems-based, with national governance receiving more attention, and it will continue to be shaped by economic shocks and political crises. Ultimately, however, the direction of social protection will vary across countries and evolve over time, as capacities to deliver fluctuate and as governments and political ideologies change. In light of these developments, the Centre for Social Protection (CSP) has identified several important recommendations for policymakers.

Since the introduction of 'social safety nets' in the 1980s, social protection has expanded greatly as a part of social policy. The rapid rise of social protection up the development agenda in the past 15 years raises questions about whether its current prominence will be sustained, or whether it will turn out to be just another development fad that declines and ultimately disappears. If social protection does remain high on the agenda, what path will it follow, who will drive it forward and what will be the main issues and challenges it faces?

An engaging research project, informed by interviews, online discussions, workshops and a literature review, provided insights into the pathways of social protection until now, the main current debates and likely scenarios for the future.

\section{Where are we and how did we get here?}

At national level, the numbers of social protection programmes and recipients of support are constantly expanding and more countries are adopting National Social Protection Strategies or Policies every year. At international level, in 2012 alone three influential agencies - the European Union, UNICEF and the World Bank - released major social protection strategy statements.

\begin{abstract}
Social protection refers to the combination of formal and informal initiatives that provide income or in-kind transfers in combination with other forms of support to poor and vulnerable households, to: (i) act as a safety net for extremely poor people; (ii) protect vulnerable people against risks and consequences of livelihood shocks; (iii) promote poor people out of poverty; and (iv) support social justice for more equitable outcomes for all. Common indicators for measuring the expansion of social protection include the number of social protection programmes in place, the percentage of the population covered by such programmes and the proportion of public expenditure allocated to social protection.
\end{abstract}

The International Labour Organization's (ILO) recommendation concerning National Floors of Social Protection was also adopted by the International Labour Conference in 2012.

The experiences with social protection in the last two decades offer insights into its trends and pathways:

Social protection is moving from being ad hoc and reactive to systematic and coordinated

Social protection has moved a long way, from the 'social safety nets' of the 1980s through to the rights-based 'Social Protection Floor' that was adopted by all of the ILO's 183 member states in 2012. As social protection has evolved from a set of uncoordinated ad hoc projects to a more holistic vision of
"The rapid rise of social protection up the development agenda in the past 15 years raises questions about whether its current prominence will be sustained, or whether it will turn out to be just another development fad that declines and ultimately disappears." 
society, so the need for a systemic approach with social protection linked to other social and economic sectors has become increasingly recognised. This is reflected in several recent social protection strategies of governments and agencies - for example, the title of UNICEF's policy framework, published in 2012, is 'Integrated Social Protection Systems'.

Social protection is developing at its own pace and following diverse paths across the world Social protection is at different stages of development in different regions, from limited coverage in low-income countries with high needs but limited financial resources through to consolidated systems in middle-income countries, with relatively well-developed social assistance and social insurance mechanisms. In some countries in Latin America, social protection started in the 1920s with contributory social insurance for formal sector workers, but has more recently become dominated by government-run conditional cash transfer programmes such as Bolsa Familia in Brazil.

Asia is a very diverse region with varied approaches to social protection. Social insurance for formal workers has been dominant in East and Southeast Asia since the mid-twentieth century, while social assistance is more prevalent in South Asia, with recent shifts from food to cash and towards rights-based approaches. There is also a long-standing balance between assistance and insurance in Central Asia, while food and fuel subsidies absorb much of the social protection budgets of countries in the Middle East.

Social protection in Africa evolved out of humanitarian relief interventions such as food aid and public works, but has recently seen a rapid proliferation of unconditional cash transfer projects, though coverage remains extremely low.

\section{Social protection is driven and shaped by a myriad of factors}

Drivers of change that might influence social protection in the coming years can be identified across five broad categories: social, technological, economic, environmental and political - 'STEEP'.

Relevant social factors that drive change include rising inequality, demographic shifts (both ageing and youthful populations), migration and urbanisation, all of which will shift the nature of vulnerability and patterns of need for social protection. Technological advances are likely to lead to enhanced delivery of social protection, while the spread of social media could improve awareness of social protection rights and enforce government accountability. A positive economic factor is (progressive) economic growth while negative drivers include economic volatility and increasing 'flexibilisation' of labour markets, with the associated loss of social security benefits. Climate change and its unpredictable consequences for rural livelihoods is the main environmental factor that is changing the way we live. Finally, political factors are on many levels, from trends in multilateral and bilateral development policies and aid flows to political commitment at national level.

\section{Where are we going?}

It is never easy to predict the future, but a few projections can be made with some degree of confidence.

\section{Social protection is likely to experience further expansion in the future}

Based on responses from policymakers and practitioners who participated in the online discussion event, 87 per cent anticipated that social protection will grow in the next decade from its present position on the development policy agenda. The remaining 13 per cent thought that it would stabilise or even decline. However, it was the positive response that was confirmed in other interviews and workshops. Social protection will grow because there will be a continual increasing need for it. Social protection can help in bridging inequality and reducing vulnerability, and it can function as a stabilising force post-crisis (economic and political) and address social exclusion of the poorest. In addition, social protection is increasingly gaining political support. This is clear by the rapid increase in the number of developing countries that are introducing social protection programmes.

\section{Social protection will become increasingly systems-based}

This applies especially in middle-income countries. Projects and programmes will increasingly become components of integrated systems with linkages to other social and economic sectors and (where appropriate)
"Social protection is at different stages of development in different regions, from limited coverage in low-income countries with high needs but limited financial resources through to consolidated systems in middle-income countries, with relatively welldeveloped social assistance and social insurance mechanisms." 
People will not tolerate the rising inequalities. Governments will have to find credible ways to show they care for their people. Social protection is an effective and transparent way to reduce inequalities. Some governments will use it to buy votes, and why not? But more and more governments realise that social protection also boosts aggregate demand, inclusion and social mobility - without which sustainable economic growth will not be feasible. (Timo Voipio, Ministry for Foreign Affairs Finland)

harmonised financial and technical support from development partners. Challenges of affordability and extending coverage will persist in low-income countries - there might even be reversals in unfavourable economic and political contexts.

\section{Social protection will continue to be shaped} by economic shocks and political crises

Whether at national, regional or global level, economic shocks and political crises will invariably contribute to the shape of social protection. They will motivate increasing investments in building systems to protect people against the consequences of these shocks, or they may undermine the deepening of social protection systems - this could go either way

Social protection will increasingly become a response to income inequality and social inequities

Social protection was initially driven solely by poverty and demographic vulnerabilities, but this is changing. It is not yet clear whether rights-based approaches towards universal provision underpinned by justiciable legislation such as the Social Protection Floor, will gain traction globally or only in certain countries.

\section{Governance of social protection will gain increasing attention}

Decentralised programming, the role of civil society, and bottom-up social accountability mechanisms will become increasingly important. Development partners will need to redefine their role, probably moving away from financing social protection projects directly and building the evidence base on impacts, towards innovative approaches to technical support and building national capacities.

\section{The direction that social protection takes will vary from country to country and will shift over time}

As capacities to deliver fluctuate and as governments and political ideologies change, the direction of social protection will vary. Better understanding of political processes around social protection, and innovative approaches to building institutional capacity, are essential to consolidate progress and to exploit both 'progressive' periods and times of austerity as windows of opportunity for reshaping social protection, as it moves forward into its next phase.

\section{Scenarios}

A scenario building exercise identified progressive or regressive politics at national and international levels, and high or low institutional capacity at national level, as key factors for predicting possible future directions of social protection. The single most important factor is probably the nature of a country's political regime.

A progressive government will be open to rights-based approaches such as the Social Protection Floor and employment guarantee schemes, civil society mobilisation and accountability mechanisms. Low institutional capacity can be partly rectified with the support of development partners, especially if the international political climate is also progressive

Conversely, politically regressive governments will reject rights-based approaches in favour of minimalist safety net approaches such as food banks, public works projects and limited conditional cash transfers. The economic and political contexts will be conducive to business and the private sector, and contributory social security for formal employees is preferred to large-scale social assistance programmes such as social grants.

The exercise revealed that the role of the international political regime is likely to be limited. While it may be important in creating an environment for progressive and innovative policy design (through the launch of global initiatives such as the Social Protection Floor and provision of technical assistance, for example), it is unlikely to be a decisive factor in shaping national social protection landscapes.
"Relevant social factors that drive change include rising inequality, demographic shifts (both ageing and youthful populations), migration and urbanisation, all of which will shift the nature of vulnerability and patterns of need for social protection." 


\section{Policy recommendations}

There needs to be increasing efforts by development partners to support governments with capacity strengthening to ensure effective implementation of programmes and pave the way towards building systems. Donor agencies and some governments are becoming preoccupied with building national systems for social protection. Efforts to increase donor coordination need to be strengthened to avoid duplication of efforts and competing donor agendas, though this requires adequate capacity which is often lacking, as well as coordination among development partners.

Social protection strategies need to be accompanied by fiscal policies that aim to increase the revenue base as economies are growing, and expand tax-based financing of social protection. The challenge of fiscal affordability remains a major barrier to the expansion and sustainability of social protection, especially in lowincome countries with high levels of poverty and vulnerability but a low tax base.

Work is urgently needed to improve the understanding of political processes around social protection policy, including the roles of civil society and social accountability mechanisms and the challenge of delivering social protection in fragile states, given that much attention has focused on 'building the evidence base' and not enough on understanding the political drivers that result in social protection being either adopted or resisted by governments.

Links with labour markets need to be strengthened, firstly by enhancing access to employment opportunities through social protection, secondly by extending social insurance to the informal sector, and thirdly by replicating 'graduation' programmes that deliver packages of social protection plus livelihood support to move people out of extreme poverty.

More investment and advocacy are needed to reach those who are currently excluded from social protection. Despite its rapid rise as a development policy agenda, actual coverage of social protection programmes remains very low, especially in low-income regions such as sub-Saharan Africa. This will include a shift away from only targeting social protection to the extremely poor, towards extending it to all social groups, particularly in middle-income countries with rising economic growth and growing middle classes.

\section{Further reading}

Devereux, S.; Roelen, $K_{\text {. and }}$ Ulrichs, M. (2014) Where Next for Social Protection?, IDS Evidence Report 124, Brighton: IDS Gentilini, U. and Omamo, S.W. (2011) 'Social Protection 2.0: Exploring Issues, Evidence and Debates in a Globalizing World', Food Policy 36: 329-40

\section{Credits}

This IDS Policy Briefing was written by Stephen Devereux,

Keetie Roelen and Martina

Ulrichs and edited by Vivienne

Benson. It was produced as part of the IDS Policy Anticipation,

Response and Evaluation

programme, supported with UK aid from the UK Department for International Development.

The opinions expressed are those of the authors and do not necessarily reflect the views of IDS or the UK government's official policies.

Readers are encouraged to quote and reproduce material from the IDS Policy Briefing series. In return, IDS requests due acknowledgement and quotes to be referenced as above.

AG Level 2 Output ID: 260

(C) Institute of Development Studies, 2015 ISSN 1479-974X 